\title{
Staphylococcus Aureus Thigh Abscess in A Systemic Lupus Erythomatosus Young Adolescent Patient
}

\author{
Talib S H ${ }^{1}$, Pagar Bhushan ${ }^{2}$, Punde Gaurav ${ }^{3}$, Hegde Rohan ${ }^{4}$, Gunthe Sudarshan ${ }^{5}$ \\ ${ }^{1}$ Professor \& Head of Medicine, Department of Medicine MGM Medical College, Aurangabad, 431003, India \\ ${ }^{2,3,4,5}$ Post graduate Residents in Medicine, Department of Medicine MGM Medical College, Aurangabad, 431003, India
}

\begin{abstract}
Systemic lupus erythematosus (SLE) rarely present as a soft tissue localized abscess. Occurrence is further rare in young adolescent age as there are finger countable cases in the world literature. The abscess was treated with combination of antibiotics and surgical drainage successfully.
\end{abstract}

Keywords:

\section{Case Report}

A 19 yr Old girl was hospitalized with the diagnosis of SLE based on presence of Butterfly rash, mouth ulcers, photosensitivity, proteinuria, Antinuclear antibodies (nuclear homogenous pattern), dsDNA antibodies, arthralgias of small and large joints and anemia ( $\mathrm{Hb} 9.2 \mathrm{gm} \%$ ) fulfilling the ACR classification criteria for SLE, 7/11. There was no previous history of medication use, radiation, drug abuse, surgery trauma or infection. She was under treatment as a case of SLE with prednisolone $2 \mathrm{mg} / \mathrm{kg}$ /day. Initially, she was on Hydroxychloroquine, the dose of steroids was tapered to $15 \mathrm{mg}$ alternate day which the patient was receiving on her hospitalization. She did not receive Azathioprine/ cyclophosphamide. She offered history of insidious pain in the middle of right thigh without cramps and fever or apparent trauma past 4 days. The physical examination revealed mouth ulcers, malar rashes, stomatitis, joint pains, localized muscle tenderness and woody indurations. However, there was no rise in local temperature or oedema. T he laboratory test revealed $\mathrm{Hb} 9.2 \mathrm{gm} \%$, HCT
$27.1 \%$, WBC 6400 / cumm ( $85 \%$ neutrophills, $12 \%$ lymphocytes and $2 \%$ monocytes), Platelet count $1,71000 /$ $\mathrm{cmm}$. ESR $52 \mathrm{~mm}$ first hour, proteinuria ++, urea $25 \mathrm{mg} / \mathrm{dl}$ and creatinine $0.9 \mathrm{mg} / \mathrm{dl}$. The muscle enzymes tests were normal. Alanine aspartate, creatinine kinase and amino transferase were within normal limits. ANA and anti dsDNA was positive. The high frequency ultrasonography of right side thigh lateral medial aspect showed collection of $350 \mathrm{cc}$ in between vastus medialis and gracialis suggestive of an abscess( Figure-1). Blood culture did not identified any organisms. As the pain in the middle thigh was excruciating patient was subjected to incision and drainage of abscess and $300 \mathrm{cc}$ could be drained. The pus culture revealed staphylococcus aurius. Treatment with IV cefuroxime 1.5 gm BD and metronidazole $500 \mathrm{mg} 8$ hry was administered for 7 days. She was discharged after one week on oral steroids in tapering doses of prednisolone $0.5 \mathrm{mg} / \mathrm{kg} /$ day with cyclophosphamide $2 \mathrm{mg} / \mathrm{kg}$ / day with lincomycin for 7 days. Patient had a sound recovery after clinical treatment.

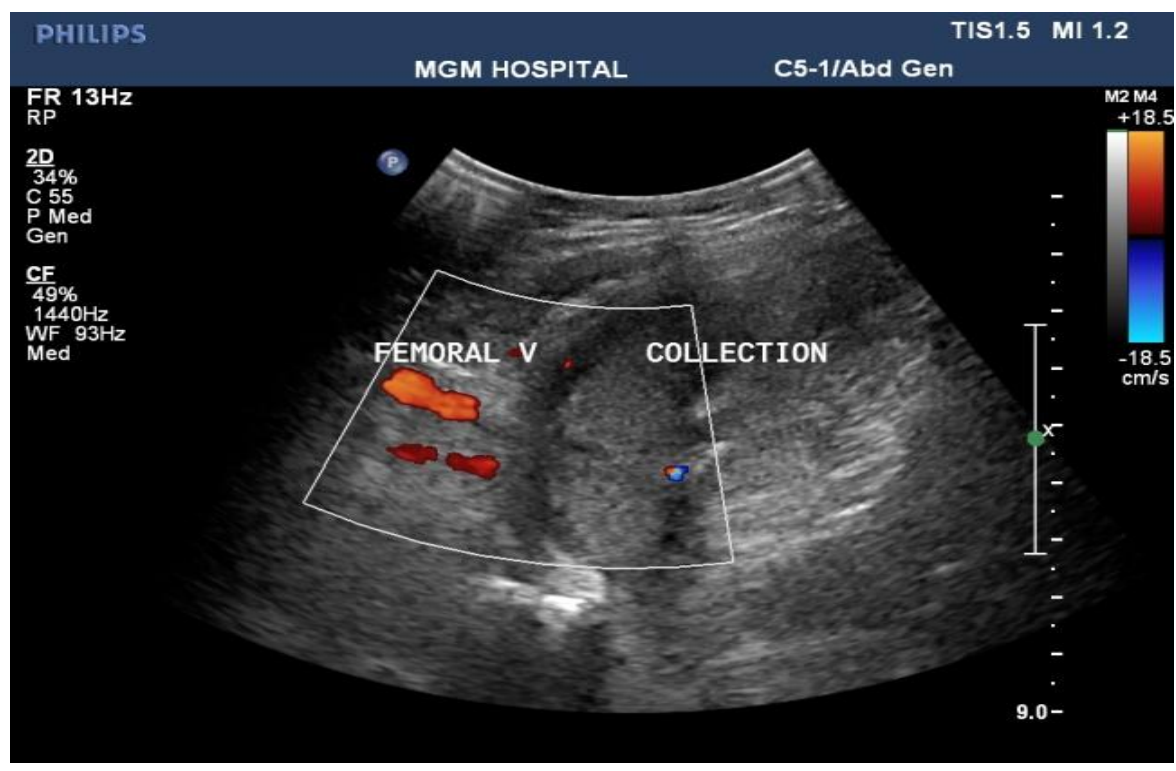




\section{International Journal of Science and Research (IJSR) \\ ISSN (Online): 2319-7064}

Index Copernicus Value (2013): 6.14 | Impact Factor (2014): 5.611

Legend to figure (1)- High frequency ultrasonography of Lateral medial aspect of right thigh showing elongated collection (pus) seen in between vastus medialis and Gracialis.

\section{Discussion}

SLE is one of the diseases thought to predispose to several severe infections like salmonella, Nocardia, tuberculosis, staphylococcus aureus, streptococci species \& E.coli 1, 2, 3, 4 . SLE patients have an increased risk of infections due to immunological dysfunction and use of chemotherapy and immunosuppressive agents. Despite increase propensity of SLE patients to develop opportunistic infections, the muscle infection - pyomyositis and localized muscle abscess are rarely observed with the disorder. The presence of localized pyomyositis or abscess detection are unlikely to be considered a vital feature during the initial differential diagnosis. The delay in diagnosis may result in increased significant morbidity and sometimes mortality. The present patient had thigh abscess caused by staphylococcus aureus. The antibiotics were given inaccordance to sensitivity report. Tung Chen $\mathrm{Y}$ and Isenberg D described necrotizing fasciitis in SLE and describe 32 cases, staphylococcus aureus was noted in only 1 case. $^{5}$ Blay $G$ et al in 2014 reported a case of purulent stage of pyomyositis in the middle third of vastus medialis without elevation of muscle enzyme where in computer tomography of left thigh showed collection of pus. The author claims the case as first ever described in the lupus population in pediatric age group in april 2014. The present case is similar to one described by Blay $\mathrm{G}$ et al who presented as a case of SLE as per American college of rheumatology ACR classification criteria ${ }^{6}$.The patient presented with localized severe muscle pain with induration in the right middle aspect of thigh. On ultrsonography the lesion revealed elongated collection in intramuscular plane in medial aspect of right upper thigh between vastus medialis and Gracialis. The drainage with the aid of ultrasound yielded $300 \mathrm{cc}$ frank pus, On microscopy contained abundant pus cells and leukocytes. The pus culture revealed staphylococcus aurius. The muscle enzymes were not elevated in the case.

The infectious myopathy was first described in 1885 by Scribba $^{7}$, with most affected regions are thighs and hips. Review of data from jan 1983 to july 2013 revealed only one case $(0.34 \%)$ with pyomyositis episode with SLE in young adolescents ${ }^{8}$. Similar clinical features may also occur in healthy patients after local trauma and may be associated as non specific pyomyositis with associated diseases like leukemia, diabetes, scleroderma, HIV, renal disorders. However, to the best of our knowledge and review of world literature, occurrence of pyomyositis / localized abscess in young adolescent lupus cases remains a rarity. The differential diagnosis of such localized pyomyositis affecting thigh includes deep venous thrombosis, hematoma, cellulitis, osteomyelitis etc. Intravenous broad spectrum antibiotics and per cutaneous surgical incision and drainage remains the main orchestra of treatment besides primary management of the underlying disease. Our patient had complete recovery after clinical treatment.

\section{Conclusion}

A case of staphylococcus abscess in right middle thigh of a young adolescent patient with SLE is described. The case emphasizes the importance of paying due attention to localized muscle pain in immune compromised patient even without the elevation of muscle enzymes which raises the suspicion of underlying abscess and demands ultra sonographic or CT imaging in the case. A prompt antibiotic therapy is warranted besides incision and drainage. The muscle infection is rarity in this adolescent young age group who are presenting with SLE.

\section{References}

[1] Shamiss A, Thaler M, Nussinovitch N, Zissin R, Rosenthal T.Multiple Salmonella enteritidis leg abscesses in a patient with systemic lupus erythematosus, postgrad Med J (1990)66, 486-488.

[2] Mitsionis GI, Manoudis GN, Lykissas MG, Sionti I, Motsis E, Georgoulis $\mathrm{AD}$, et al.Pyomyositis in children:early diagnosis and treatment.J Pediatr Surg.2009;44:2173-8.

[3] Souza HC, Carvalho BN, Morais MG, Monteiro GZ, Emori FT, Latorre LC. Tropical pyomyositis in a patient with systemic lupus erythematosus and HTLV 1/2 infection. Rev Bras Reumatol. 2011 Jan-Feb;51(1):97103.

[4] Hara H, Wakui F, Ochiai T. Disseminated Nocardia farcinica infection in a patient with systemic lupus erythematosus. J Med Microbiol. 2011 Jun;60(Pt 6):847-50.

[5] Tung Chen Y, Isenberg D.Necrotising fasciitis in systemic lupus erythematosus: a case report and literature review.. Lupus Sci Med. 2014 May 10;1(1):e000008. doi: 10.1136/lupus-2014-000008. eCollection 2014.

[6] Hochberg MC Updating the American College of Rheumatology revised criteria for the classification of systemic lupus erythematosus. Arthritis Rheum. 1997 Sep;40(9):1725.

[7] J. Scriba.Beitrag zun aetiologie der myositis acute.Dtsch Z Chir, 22 (1885), pp. 497-502.

[8] Gabriela Blay, Mariana P.L. Ferriani, Izabel M. Buscatti, Camila M.P. França, Lucia M.A. Campos, Clovis A. Silva. Pyomyositis in childhood-systemic lupus erythematosus.open acessRevista Brasileira de Reumatologia (English Edition) Available online 27 November 2014. 